\title{
O BRANDING EM TEMPOS DE CROSS-MEDIA: UM OLHAR DO DESIGN GRÁFICO
}

\author{
Ceccato, P.; Aquino, D.; Gomez, L. S. R.
}

\section{RESUMO}

0 presente artigo expõe a importância de se explorarem diferentes mídias, inclusive a internet, com suas redes sociais, na gestão de marcas - ou branding -, visando estabelecer uma relação de interatividade entre empresa e consumidor, permitindo a participação deste último na tomada de decisões da marca. 0 objetivo é mostrar com o design gráfico deve atuar nessa realidade de cross-mídia, visando manter a unidade visual da marca nos diferentes veículos de comunicação para não enfraquecer sua mensagem emocional. A metodologia empregada para o desenvolvimento deste artigo foi a pesquisa bibliográfica, que resultou numa análise descritiva e interpretativa dos dados teóricos coletados. Branding, atualmente inserido na realidade da cross-mídia, deve ser feito pelo marketing, publicidade e design em conjunto, com a colaboração com consumidores, o que pode ser providenciado pelas redes sociais. É época de fazer parte da vida do consumidor, e o deixar participar da vida da marca.

Palavras chave: história em quadrinhos, história, design e quadrinhos.

\section{ABSTRACT}

This paper presents the importance of exploring different media, including the internet, in brand management - called here branding - to establish an interactive relationship between company and consumer, allowing his participation in the decision-making process of the brand. The goal is to demonstrate how graphic design must act in this reality of cross-media, in order to maintain the visual unity of the brand in different communication vehicles not to weaken its emotional message. The methodology used to develop this paper was the literature search, which resulted in a descriptive and interpretational analysis of the theoretical data collected. Branding currently inserted in the reality of cross-media, must be done by marketing, advertising and design together, in collaboration with consumers, which can be provided by the social networks. It is time to be part of consumer's life, and let them participate in the brand's life.

Key-words: branding, cross-media, graphic design.

\section{INTRODUÇÃO}

0 presente artigo expõe a nova realidade que se apresenta à gestão de marcas: de comunicação globalizada, mas buscas individualizadas. Realidade possibilitada pela interação entre marca e consumidor permitida pelo cross-mídia: na qual o designer precisa pensar em um plano de ação geral, mas prever as possibilidades de comunicação da marca em diferentes mídias, incluindo a internet.

O objetivo é explorar o branding através do cross-mídia e chegar ao consumidor pelos diferentes 
veículos de comunicação, adaptando a campanha às limitações e abrangência de cada um. Não só as estratégias de marcas são importantes, mas também os canais para comunicação das mesmas. Nas palavras de Svein Haakon Lia (2009), diretor de criação e sócio-fundador do estúdio norueguês Oslo, "quase todas as identidades que fazemos terminam em mídias diferentes da impressa", conta, e "99\% são soluções customizadas para web". 0 diretor conta que pensar em diferentes mídias, sobretudo na internet, gera competitividade no mundo da gestão de marcas.

Segundo Gobé (2010), "as marcas precisam conectar-se com a cultura e alcançar o coração das pessoas". Sendo assim, o designer precisa conhecer seu público-alvo interpretando suas necessidades e estando atento às mudanças das diversas mídias a que tem acesso e dos serviços de dispositivos moveis, bem como da internet, que está em constante evolução.

0 designer gráfico atua nessa realidade com um olhar criativo nos projetos de marca, visando manter a unidade e a identidade visual nas diferentes mídias, atuando como facilitador da expressão da identidade de marca. As empresas que valorizam o design obtêm soluções mais eficazes num mercado interativo, onde é indispensável a atuação e a integração das diversas áreas de gestão e comunicação que envolve a marca.

0 presente artigo abrange, portanto, as áreas de conhecimento ligadas ao design, marketing e a publicidade, buscando entender e co-relacionando as habilidades de ambas com a gestão estratégica de marcas, que permite às marcas obter vantagens perante a competitividade empresarial na economia atual. São buscados, dentro de cada área, tópicos específicos que irão nortear o embasamento teórico da pesquisa, para expor como branding, que se refere à gestão e ao posicionamento estratégico de marcas, pode se destacar como um ativo essencial das empresas na valorização dos produtos e serviços no universo crossmídia, ou seja, nos diversos veículos de comunicação da atualidade.

Objetiva-se, portanto, expor a nova realidade cross-midiática de comunicação que se apresenta às marcas, e como elas atualmente precisam criar estratégias de branding que explorem diferentes mídias, incluindo a internet e as redes sociais de acordo com seu público-alvo. Também expomos o papel do designer gráfico nesta realidade: criar uma mensagem emocional e manter a unidade visual nas diferentes mídias.

Para realização deste trabalho, o método de pesquisa empregado foi a investigação bibliográfica, que envolve referências das áreas do design gráfico, branding, marketing e comunicação. A proposta foi realizar uma pesquisa descritiva e interpretativa dos dados bibliográficos, visando analisar a realidade crossmidiática e suas implicações nas marcas. "A descrição faz a ponte entre a fase de observação dos dados e a fase da interpretação." (LOPES, 1990, pág. 129)

Portanto, segue-se à descrição dos dados coletados, a interpretação dos mesmos à luz da bibliografia pesquisada. De acordo com Immaculata Lopes. “a interpretação é a segunda etapa da análise e com ela a pesquisa atinge a condição própria de cientificidade" (LOPES, 1990). Neste trabalho, por conseguinte, os dados bibliográficos coletados sobre cross-mídia são descritos e posteriormente interpretados sob o viés da gestão de marcas, visando analisar a relação entre o fenômeno do cross-mídia e suas implicações para a gestão de marcas. 


\section{CONTEXTUALIZAÇÃO}

A profunda mudança no mercado de comunicação está mexendo com a percepção dos profissionais de design relativa à gestão de marcas, e influenciando o marketing e a publicidade no mundo dos negócios, já que este processo é acelerado pelo advento de novas tecnologias, que ocasionam mudanças nos hábitos de consumo, e na relação com a mídia por seus consumidores.

A cross-mídia nasce a partir da constatação de que o consumo mudou. A possibilidade de interagir uns com os outros em tempo real através da internet, deu aos consumidores um poder que altera de forma dramática a maneira como se deve planejar branding, já que as marcas precisam também participar desta interação, e não apenas veicular conteúdo que o consumidor, atualmente, não aceita mais passivamente. De acordo com Gobé (2007), "o mundo mudou de uma perspectiva empresarial, de consumo e mídia. Globalização, concorrência de preços, queda nos lucros, maior fragmentação da audiência dos veículos de comunicação, excesso de oferta de novos produtos, distribuição mais variada de ofertas e o ciclo de vida mais curto das inovações" levaram as empresas a repensar suas estratégias, sobretudo as de comunicação, já que as mídias tradicionais, como televisão, rádio, anúncios impressos e outdoors, passaram a enfrentar a concorrência da televisão a cabo, redes sociais, web, blogs e podcasts1.

Com esta nova perspectiva de mercado, se faz necessário um maior entendimento das características do consumidor em sua busca por produtos e serviços. Segundo Qualman (2009) "essas gerações de consumidores tem noção do seu lugar na comunidade global e são mais criativos e cooperantes" e o autor afirma que a tecnologia é parte intrínseca das suas vidas. Fica claro que os consumidores querem interagir e apropriar-se das marcas. 0 autor escreve sobre a geração do milênio que é também designada como as gerações X e Y, que estão totalmente sintonizadas a esta nova era o digital.

É necessário o entendimento das marcas e como elas estão sendo diferenciadas no mercado atual, e entender sua dimensão comunicativa sabendo que elas existem porque podemos reconhecê-las, e que as reconhecemos porque percebemos as mensagens que elas enviam, suas especificidades, seus valores intangíveis que possuem certa constância ao longo do tempo.

A internet trouxe a mudança e a ruptura de um modelo de comunicação e de negocio gerando a migração para o mundo digital, fazendo com que mais empresas descubram e participem das redes sociais e busquem estreitar o relacionamento com seu publico consumidor, fortalecendo a mensagem da marca e o vínculo entre eles. Segundo Manoela Amaro (2009), diretora de marketing da TAM, a marca "deve compor uma estratégia multicanal para maior efetividade, porém concordamos que é possível trazer experiência e relacionamento, além de somente a venda, por meio da web". Algumas marcas já reconhecem que é preciso criar um posicionamento adequado perante o mercado através das novas mídias digitais, além das tradicionais. 


\section{CROSS-MÍDIA E AS REDES SOCIAIS}

Primeiramente temos que entender o termo mídia, que deriva do latim media, e quer dizer meio. Ou seja, a mídia como entendemos agora, é um meio de comunicação. Segundo Lima (2001), mídia significa o conjunto de instituições que utilizam tecnologias especificas para realizar a comunicação humana. A mídia implica na existência de um intermediário tecnológico para que a comunicação se realize. Na mídia tradicional - televisão, rádio, material impresso - o espectador era mero receptor da mensagem, sem a real possibilidade de interagir com o veiculador. Porém, isso mudou após o advento da internet, principalmente. Atualmente existem muitos meios para a difusão de mensagens que permitem a interação do receptor.

Com o breve entendimento do termo mídia podemos falar do termo cunhado por Frazão (2006), midialização que segundo ele "trata-se de uma publicação sobre mídias, que objetiva alguns dos principais lances da mídia moderna e tenta retratar a atual configuração dos canais de comunicação em todo mundo, exatamente como a globalização fez e faz com a economia mundial", "o termo se renova a cada instante em que um novo canal de comunicação ganha um novo formato e conteúdo", para facilitar a vida da empresa e a do consumidor. 0 termo surgiu a exemplo de outro: globalização, que define a economia global. Midialização define a economia pautada na mídia.

0 atual mercado da midialização é constantemente impulsionado por novidades. Para explicar esta condição são criados diferentes conceitos, além do próprio, como, por exemplo, o de cross-mídia, que apesar de diferentes definições possui "um significado comum que se traduz como o uso de múltiplos meios para propagar uma mesma mensagem com o objetivo de tornar o conteúdo mais acessível” conforme diz Boumans (2004). Na opinião de Wiberg e co-autores (2007), "um fenômeno visto como uma mensagem contada em mais de uma mídia" também é chamado de cross-mídia.

Se na área de marketing o termo significa usar múltiplos canais de comunicação, quando é usado no design gráfico, especificamente na Web, o termo é associado a mais de uma plataforma técnica, o que proporciona o acesso de mais pessoas aos diversos tipos de dispositivos. 0 conceito de cross-mídia (ou cross media, termo original em inglês) vai adquirindo novas características à medida que é explorado por áreas distintas. Para Filgueiras e co-autores (2008) a definição adotada é a seguinte: “cross media é o suporte colaborativo de várias mídias para entregar uma única história ou tema, no qual o enredo direciona o receptor de um meio para o outro, de acordo com a força de cada meio para o diálogo".

A cross-mídia possui cinco características que a definem, listadas por Boumans (2004): (1) a crossmídia envolve mais de uma mídia; (2) a cross-mídia objetiva uma produção integrada; (3) o conteúdo é entregue em múltiplas mídias; (4) mais de uma mídia é necessária para apoiar uma única mensagem/narrativa/meta; (5) a mensagem/narrativa/meta é distribuída em múltiplas plataformas e a interação apoiada pode acontecer nestas diferentes plataformas.

Conforme o número de meios de comunicação aumenta, clientes bem informados pedem cada vez mais por uma solução cross-mídia, que nada mais é do que pensar numa ação ou mensagem prevendo a possibilidade de comunicação em diferentes mídias, de forma que elas se complementem, atingindo, assim, um publico alvo mais amplo. 
Citando a reportagem da revista Computer Arts, a maioria dos projetos do estúdio norueguês Oslo são cross-mídia. "Quase todas as identidades que fazemos terminam em mídias diferentes da impressa", conta o diretor de criação e sócio-fundador Svein Haakon Lia (2010). 0 diretor conta que a cross-mídia pode ser um beneficio para os designers: "faz com que você possa pensar em conceitos mais enxutos, dramatizados de forma diferente em cada mídia". Fala-se, então, sobre a cross-mídia: uma estratégia promocional que estimula a interatividade do público através da utilização de vários recursos relacionados.

Para que as ações de cross-mídia atinjam o objetivo desejado, é importante ligar a publicidade ao conteúdo online. Com a publicidade difundida na internet, algumas ações de marca ganham forma e passam a ser disseminadas em larga escala, o que as torna parte das estratégias de marketing digital da maioria das empresas que deseja desenvolver suas marcas através da internet.

A cross-mídia não abandona as mídias tradicionais, ao contrário do que dizem as críticas que decorreram dessa estratégia. Ela, ao contrário, representa uma atuação democrática em diferentes mídias enquanto utiliza todas as melhores ferramentas de comunicação de cada veículo. Em outras palavras, a cross-mídia nada mais é do que a convergência das mídias para fins de divulgação de uma marca ou dos seus produtos e serviços.

Atualmente, após o advento e a popularização da internet, estamos passando pela popularização das mídias sociais: os blogs, sites de compras coletivas, redes-sociais, sites de compartilhamento de conteúdo, wikis, mundos virtuais, jogos online, entre outros. Estas mídias se diferenciam das tradicionais porque a comunicação através delas é feita pelos próprios usuários. É uma comunicação da sociedade para a sociedade, e não de editoras, produtoras e emissoras para espectadores.

Comm (2009) define as mídias sociais como mídias em que o conteúdo é criado pelo seu público, e exemplifica: "vejamos o Facebook. Ele não é uma companhia editorial. Não cria nenhum de seus conteúdos. Não escreve ou posta artigos, e não insere filmes ou imagens para os clientes verem ou apreciarem. Ele permite que seus usuários façam tudo isso por seu próprio interesse".

"Mudamos de um mundo onde a informação e as notícias eram detidas por uns poucos e distribuídas para milhões, para um mundo onde a informação é detida por milhões e distribuída a uns poucos (nichos de mercado)" (QUALMAN, 2010). Ou seja, os jornais, revistas, emissoras de rádio e canais de televisão estão dividindo cada vez mais espaço com a internet. E, para além dela, estão dividindo espaço não só com os grandes sites de notícias, portais de busca ou sites empresariais, mas, sobretudo, com os blogs e redes sociais.

Sobre as redes sociais, cabem breves exemplos de como as empresas podem se beneficiar delas, apoiadas nos conceitos de Recuero (2009), sobre as redes sociais mais utilizadas da web - Orkut, Fotolog, Facebook e Twitter. Quando as empresas fazem uso do Orkut, elas têm a possibilidade de criar perfis e comunidades através dessa rede social criada em 2004; Já o Fotolog, criado em 2002, possibilita a publicação de fotografias acompanhadas de textos que podem receber comentários; No Facebook, de 2004, além da possibilidade de criar rede de contatos, ele funciona através de perfis e comunidades nas quais é possível acrescentar aplicativos, o que abre espaço para a personalização do mesmo e, no Twitter, criado em 2006, as empresas podem a partir de 140 caracteres, divulgar produtos, serviços, eventos etc. para seus seguidores. 
Sobre as mídias sociais:

O desafio dos lideres na globalização amplia os limites organizacionais [...], e essa nova tecnologia incrementa drasticamente tanto a oportunidade de conectividade entre as pessoas como a demanda por parcelas da atenção delas. [...] Os lideres podem aproveitar novas ferramentas em um sentido amplo, para lidar com esses desafios de maneira criativa. (LEMOS; PALÁCIOS, 2001)

Desta forma, é importante para uma marca manter a interação com seu público-alvo através de análises constantes da opinião dos consumidores na rede. Isso enfatiza a importância da seleção, planejamento, gerenciamento e avaliações permanentes nas mídias sociais.

O consumidor está tomando suas próprias decisões com base nas próprias avaliações que faz sobre as marcas. Todo ano chega ao mercado uma leva de consumidores cada vez mais interada, possuindo um alto grau de familiaridade com a tecnologia e os novos veículos de informação. De acordo com Aldrich (2000), as empresas da era digital devem empregar os processos de desenvolvimento de produtos que interagem dinamicamente com os clientes; elas devem executar um monitoramento mais constante e preciso das tendências globais de mercado.

Para entender isso completamente, temos que observar o que impulsiona a demanda do consumidor na economia digital e em seus diversos veículos de comunicação. Esclarece Morace (2009) que as novas tecnologias têm contribuído para modificar os comportamentos "mentais" que cada um tem absorvido como novos parâmetros de pensar, do decidir e do avaliar. Para Ramos (2008), o consumidor atual pode levar um produto ou serviço ao sucesso ou ao fracasso com um comentário no seu blog ou comunidade no Orkut.

Reforçadas pelas constantes mudanças de comportamento e de hábitos do consumidor, o mundo das mídias e da comunicação deverá atender as expectativas sempre mais exigentes de um sujeito com um novo espírito crítico, criativo e colaborativo no qual não existe um único estilo a ser seguido. Abaixo o autor expõe as mudanças dos consumidores:

Trata-se de uma convergência que vivenciamos a partir do digital: o feliz encontro entre empresa, consumo e projeto. Na perspectiva de uma existência futura para empresas e pessoas, o mundo e as tendências do consumo não demonstraram a autonomia de valor que expressaram nos últimos vinte anos, mas contribuem profundamente para o lançamento de um leque de valores novos e experimentos e parâmetros sugeridos e sustentados pelas novas tecnologias. É assim que encontramos o mundo dos novos consumidores autorais. (MORACE, 2009).

Este consumidor está desejando, querendo, provocando, revolucionando, impondo novas regras no mercado, e o designer precisa entender e decodificar estes anseios e lidar com a sua instabilidade, buscando estar mais próximo do publico e conquistar vantagens mercadológicas para a marca perante seus concorrentes. Chevaller \& Mazzalovo (2007) explicam: "em uma sociedade caracterizada pelo crescimento exponencial da comunicação, em todas as suas formas e conteúdos, percebe-se o fato de as marcas estarem no centro da vida contemporânea". Sendo assim, os benefícios intrínsecos proporcionados pelas marcas 
tendem a ser imagens, mensagens que os consumidores desejam, seja ela com qualidade percebida ou não. E o papel do designer gráfico é construir essas imagens, essas mensagens, nas diferentes mídias da atualidade.

\section{A INFLUÊNCIA DA CROSS-MÍDIA EM BRANDING}

Várias áreas devem assumir uma postura distinta na midialização, como é o caso do marketing, design e profissionais da área de planejamento e desenvolvimento das mídias sociais. Estes devem estar prontos para o aperfeiçoamento das mídias existentes: não devem apenas criar, mas mantê-las em desenvolvimento estrategicamente pensando na interação dos usuários.

Outro ponto que merece destaque é o papel do profissional de comunicação da área da publicidade, que de acordo com Pinto (2002), é a disciplina que se responsabiliza pela promoção da oferta, sendo que sua força provém da sua capacidade persuasiva e da sua efetiva contribuição aos esforços para mudar hábitos, criar imagens, promover o consumo, vender produtos e informar o consumidor. Sabendo-se da importância da ação em conjunto com outras áreas, o autor também afirma que depois da constatação de que as marcas estão se transformando no principal ativo das empresas, a publicidade é descrita na sua condição de ferramenta que tem um papel participativo na construção e manutenção das marcas fortes e duradouras.

Trabalhar com as mídias sociais no sentido de gerenciá-las, evidencia o papel do profissional de comunicação que é desafiado com as novidades trazidas por elas, por seus usuários. Tendo em vista sua existência recente, as regras para acompanhá-la também não estão muito bem definidas. Neste cenário, exercer a comunicação de maneira objetiva, eficaz e interativa faz toda a diferença para as marcas no estreitamento da relação com o público que cada empresa possui.

Muitas empresas estão descobrindo que as mídias sociais são meios muito eficientes para o desenvolvimento de ações de marketing, para compreender sua audiência e, assim, conquistá-la (KULPAS, 2008). 0 mínimo que se espera dos executivos é que eles conheçam muitos conceitos e estratégias, e se mantenham atualizados e receptivos a novos conhecimentos e idéias, já que isso pode fazer toda a diferença para o futuro do negócio.

Faz-se necessária, neste ponto, a abordagem do conceito de marketing. 0 autor Silk (2008) cita que "o marketing ocupa um papel central na empresa por ser o processo por meio do qual ela cria valor para os clientes que escolheu. 0 valor é criado ao se atenderem às necessidades dos clientes". Já para Honorato (2004), "fazer marketing é se relacionar profundamente com todos os públicos envolvidos com uma empresa, marca ou produto", e ainda observa que "a essência do marketing está no processo de troca". Ao se identificarem desejos ou necessidades, busca-se satisfazê-los, comprando um produto ou serviço de quem o tem para vender, estabelecendo, assim, uma troca nas quais organizações e clientes (empresas e consumidores) participam.

Kotler (2010), segundo a sua teoria, articula:

Ao longo dos anos 60, o marketing deixou de ser centrado no produto (Marketing 1.0) e passou a ser centrado no consumidor (Marketing 2.0). Hoje vemos o marketing transformando-se mais uma vez, em resposta à nova dinâmica do meio. Vemos as empresas 
expandindo seu foco dos produtos para os consumidores, e para as questões humanas. Marketing 3.0 é a fase na qual as empresas mudam da abordagem centrada no consumidor para a abordagem centrada no ser humano, e na qual a lucratividade tem como contrapeso a responsabilidade corporativa. (KOTLER, 2010)

O autor acima citado contribui afirmando a necessidade de um novo olhar para a compreensão deste novo mercado e do perfil do consumidor, que se caracteriza nas seguintes eras: a era da participação, a era do paradoxo da globalização e a era da sociedade criativa. 0 consumidor está mais próximo das empresas e influenciando e interagindo diretamente nas estratégias da marca. (KOTLER, 2010)

A área do marketing é de suma importância para a criação e gestão de marcas, ou branding. Este está também relacionado à área de estudo do design gráfico, já que o último diz respeito à criação de formas para traduzir mensagens. Branding "descreve todas as ações relacionadas ao projeto de criação ou gestão de marcas" (MARTINS, 2006) e engloba uma séria de disciplinas, entre elas as principais são o marketing, a publicidade e o design (GOMEZ; OLHATES; FLORIANO, 2010). Dessa forma, branding, segundo Sampaio (2002), poderia ser definido como "um conjunto de tarefas de marketing - incluindo suas ferramentas de comunicação - destinado a otimizar a gestão de marcas". O intuito de branding, segundo Healey (2009), "é reforçar uma boa reputação, estimular a lealdade, garantir qualidade, veicular uma percepção de maior valor, garantir uma sensação de afirmação e entrada em uma comunidade imaginária de valores partilhados".

O marketing e a comunicação passaram a ter como premissa básica a conquista e a fidelização do consumidor para, assim, fazê-lo comprar. As estratégias de branding, então, passaram a ser focadas, de acordo com Roberts (2004), em "fazer as pessoas se sentirem bem em relação à marca, para obter uma emoção positiva", além de criar um vínculo afetivo, uma relação amorosa, dando origem ao que podemos chamar de branding emocional.

O panorama atual convergente apontou o surgimento de um novo branding, o branding na era da cross-mídia, que foge da estética da redundância e visa envolver o consumidor numa relação participativa, emocional e inovadora com as marcas, utilizando a mídia em massa, mas principalmente as novas mídias vinculada à internet, como as redes sociais, os jogos online, os blogs, podcasts, sites de compras coletivas, entre outras.

É válido ressaltar, também, que a linguagem utilizada por branding visando "dialogar" com o consumidor é uma estratégia em parceria com as áreas de marketing, design e comunicação. Assim, mudamos para uma perspectiva onde o consumidor assume o papel de colaborador, co-criador, participante de fato das ações da marca. Logo, branding inserido na cross-mídia se configura como uma excelente oportunidade para as marcas se relacionarem com seu público, pois, entende-se hoje que o consumidor, cansado de ser descoberto, quer descobrir, quer buscar a informação que deseja, que desperte seu interesse e, sobretudo, suas emoções.

Relacionado a estas estratégias de marca, está o design gráfico, que, nesta realidade, pensa não somente na forma de um produto ou na forma de transmitir uma mensagem, mas pensa a própria mensagem transmitida pela marca. Segundo Gobé (2007), “o design é mais do que o veículo pelo qual as marcas se 
expressam e se conectam com os seus clientes [...] o design permeia todos os aspectos da vida, transmitindo mensagens memoráveis que inspiram a vida e causam emoção". Sendo assim, o design emocional é o novo desafio de branding: "as marcas devem mudar de 'comunicações' e 'commodities' para emoção e inspiração" (GOBÉ, 2007). Ou seja, a possibilidade de interagir com a marca deu aos consumidores um poder que altera de forma dramática a maneira como se deve planejar branding, sobretudo para o design gráfico, que precisa criar mensagens que estimulem a curiosidade do consumidor de maneira criativa, transmitam valores positivos, despertem suas emoções e criem uma experiência memorável e relevante, para que ele a compartilhe com os outros através de um blog, das redes-sociais, etc.

Sendo assim, o desafio das marcas na atualidade é a transmissão de mensagens inspiradoras e emocionais através dos novos meios de comunicação: as mídias sociais, que se diferem das tradicionais por permitirem que o próprio usuário gere conteúdo. Isso significa que estas são mídias nas quais as informações propagadas são aquelas sugeridas e recomendadas pelos próprios consumidores e não aquelas impostas pelas marcas.

De acordo com Dimantas, (2003) “encarar o cliente como alvo de fidelização é muito pouco. [...] 0 cliente quer poder interagir com a empresa de maneira mais participativa”. David Siegel, em Futurize sua Empresa (SIEGEL apud DIMANTAS, 2003) propõe uma gestão conduzida pelo cliente: “o cliente palpita, traz novidades e se autofideliza"

O objetivo das marcas, portanto, deve ser se aproximar dos consumidores; e do design gráfico, deve ser chamar a atenção deles de maneira inovadora, fazê-los criar interesse pela marca através de estímulos emocionais, abrir canais de comunicação para ouvir suas opiniões, e criar uma experiência de interação memorável, para que eles a compartilhem com outros consumidores. "O conteúdo não é mais empurrado aos consumidores, é puxado por eles" (STRINGER apud GOBÉ, 2007). "Acredito que isso se aplica à publicidade: as pessoas desejam ter mais opções de acesso às comunicações de suas marcas” (GOBÉ, 2007)

Ou seja, é hora de conversar com seus consumidores pelo Twitter, ouvir o que eles têm a dizer. Dar oportunidade para eles 'curtirem' a nova campanha da marca - veiculada no Youtube - no Facebook e compartilhá-la com os amigos. É hora de inserir o produto na narrativa de um jogo digital, ou criar um aplicativo da marca para o iPhone.

“O plano de mídia faz parte do plano geral da marca. Com a versatilidade da mídia atual, você precisa considerá-la em papéis inusitados" (KELLEY; JUGENHEIMER, 2006). E o papel agora é o de fazer parte da vida do consumidor, e o deixar fazer parte da vida da marca, criando um laço emocional através do design gráfico.

\section{CONCLUSÃO}

As mídias, de um modo geral, têm um papel mediador importante a desempenhar. Sendo assim, várias empresas que aplicaram diferentes estratégias de mídia, que visavam o contato direto com seus usuários, obtiveram um respaldo mais eficaz perante os concorrentes. 0 profissional de design é uma peça importante nesta nova realidade de mercado, trazendo um olhar criativo aos projetos de marca, visando 
manter a unidade e a identidade visual nas diferentes mídias, atuando em parceria com outras áreas, como o marketing e a publicidade.

O design nessa realidade de midialização deve ser versátil o suficiente para tocar em diversos pontos o subconsciente do consumidor. Qualquer marca precisa assegurar que haja consistência entre os anúncios impressos e online, o ambiente das lojas, a embalagem e a campanha veiculada na televisão, na rádio, no Youtube e divulgada no Twitter e no Facebook, por exemplo. 0 branding contemporâneo não busca mais somente marcas que identifiquem seus produtos. Respondendo ao ambiente de mídia atual, o marketing e a publicidade precisam criar experiências de envolvimento, de participação e de interação para cativar consumidores através do design.

O que o marketing compreendeu, nos últimos anos, é que as experiências construídas entre a marca e o consumidor são de extrema importância para se chegar num diferencial competitivo e criar laços de fidelidade e comprometimento. Ou seja, as estratégias geridas pelo branding devem permitir e integrar a aplicação de ações cross-media, nas quais os profissionais de design devem entender as diferentes formas de interação do usuário com cada mídia e analisar as diversas experiências que as mesmas o proporcionam para chegar numa solução com excelência.

Um fato que merece mais atenção nesse cenário é a questão do acesso a essas mídias sociais digitais. Para muitas marcas, dependendo qual é o seu público-alvo, não é adequado usá-las como único e exclusivo meio de interação com seus clientes, visto que existem diversos grupos consumidores e cada um deles necessita de um ponto de contato, de meios de comunicação e planejamento diferente, respeitando suas necessidades e características. Falar em democratização da informação somente através dessas tecnologias é incerto quando há pessoas que não têm acesso, ou interesse, a essa rede.

Se há alguns anos não era exatamente fácil construir e manter a imagem de uma marca no subconsciente dos consumidores para tê-los como seus fiéis seguidores, o processo de branding nos dias de hoje vem se tornando cada vez mais complexo e sofisticado, não só com a evolução das formas de expor as marcas mas, sobretudo, com o surgimento dos meios digitais. Criou-se a falsa impressão de que a propaganda seria o instrumento de comunicação quase que exclusivo para o branding. Não é. Ela exerce sim um papel essencial, de divulgação, mas hoje em dia, em um número crescente de casos, a propaganda é apenas coadjuvante do processo. "A internet permite algo que a propaganda, por mais que se esforçasse, nunca logrou conseguir: criar laços de intimidade e individualidade com seu público" Com isso, percebemos que o branding na cross-media se configura num modo diferenciado e inovador de promover a marca.

0 ponto é que o branding, atualmente inserido na realidade da cross-media, deve ser feito pelo marketing, publicidade e design em conjunto, com a colaboração com consumidores, o que pode ser providenciado pelas mídias sociais. 0 design gráfico, principalmente, precisa criar uma mensagem que transmita a identidade da marca (diagnosticada pelo marketing) nas diferentes mídias (pela publicidade) mantendo a identidade visual e de conceito. 


\section{REFERÊNCIAS}

ALDRICH, Douglas F. Dominando o Mercado Digital. São Paulo: Makron Books, 2000.

AMARO, Manoela. Citada em Intimidade e Individualidade: Internet Oferece um Algo a Mais Quando se Trata de Planejar Branding. Reportagem publicada na revista “Conexão: Microsoft Advertising" edição n 45; Novembro/dezembro de 2009.

BOUMANS, J. Crossmedia - e-content report 8. ACTeN - Anticipating Content Technology Needs, 2004.

CHEVALLIER, Michael; MAZZALOVO, Gérald. Pró Logo: Marcas como Fator de Progresso. São Paulo: Panda Books, 2007.

DIMANTAS, Hernani. Marketing Hacker: A Revolução dos Mercados. Rio de Janeiro: Garamond, 2003.

FILGUEIRAS, Lucia L. V.; CORREA, Danilo O.; NETO, João S. O.; FACIS, Renato P. X-Gov Planning: How to Apply Cross Media to Government Services. Proceedings of the Second International Conference on Digital Society, p.140-145, February 10-15, 2008.

FRASÃO, Angelo N. Midialização: O Poder da Mídia. São Paulo: Nobel, 2006.

GOBÉ, Marc. BrandJam: O Design Emocional na Humanização das Marcas. Tradução Maria C. De Biase. Rio de Janeiro: Rocco, 2007.

GOMEZ, Luiz S. R.; OLHATS, Magali; FLORIANO, Juliana. Fashion's Brand DNA: The Process. International Conference Global Fashion: Creative and Innovative Contexts. Porto, 2010.

HEALEY, Matthew. O Que é Branding? Tradução Jorge Pinheiro. Barcelona: Gustavo Gili, 2009.

HONORATO, Gilson. Conhecendo o Marketing. Barueri: Manole, 2004.

KELLEY, Larry D.; JUGENHEIMER, Donald W. Uma Visão de Mídia para Gestores de Marcas. Tradução Dinah A. Azevedo. São Paulo: Nobel, 2006.

KOTLER, Philip. Marketing 3.0: As Forças que estão Definindo o Novo Marketing centrado no Ser Humano. Rio de Janeiro: Elsevier, 2010.

KULPAS, S. Muita Gente, Pouca Grana: O Futuro ainda é Incerto para os Sites Sociais como Fonte de Receita Publicitária. Revista Meio Digital. São Paulo: M\&M, n.5, p. 52-58, Maio/junho de 2008.

LEMOS, André; PALÁCIOS, Marcos. As Janelas do Ciberespaço. Porto Alegre: Sulina. 2001.

LIA, Svein Haakon. Entre no Mundo Cross-media do Design. Computer arts brasil. São Paulo: Europa, edição 28, p. 42-46, Dezembro 2009.

LIMA, V. A. Mídia: Teoria e Política. Number 8586469602. Fundação Perseu Abramo, 2001.

MARTINS, José R. Branding: Um Manual para Criar, Avaliar e Gerenciar Marcas. $1^{a}$ Ed. São Paulo: Global Brands, 2006.

MORACE, Francesco. Consumo Autoral: As Gerações como Mmpresas Criativas. São Paulo: Estação das letras, 2009.

PINTO, J.B. Comunicação em Marketing: Princípios da Comunicação Mercadológica. São Paulo: Papirus, 2002.

QUALMAN, Erik. Socialnomics: Como os Media Sociais Estão a Transformar o Modo como Vivemos e Como Fazemos Negócios. 1aㅡ. Ed. Lisboa: Presença, 2009.

RAMOS, É. A Criação de Marcas 2.0. Revista Consumidor Moderno. São Paulo, ano 13 - n. 123, p. 24-28, Março de 2008.

RECUERO, Raquel. Redes Sociais na Internet. Porto Alegre: Sulina, 2009.

ROBERTS, Kevin. Lovemarks: Futuro além das Marcas. São Paulo: M. Books, 2004.

SAMPAIO, Rafael. Marcas de A a Z: Como Construir e Manter Marcas de Sucesso - Um guia para fazer da sua marca a principal força do seu negócio. Rio de Janeiro: Campus, 2002.

SILK, Alvin J. O que é Marketing. Porto Alegre: Bookman Companhia, 2008. 
Ceccato, P.; Aquino D.; Gomez, L. S. R. - O BRANDING EM TEMPOS DE CROSS-MEDIA: um olhar do design gráfico

WIBERG, C.; BODÉN, J.; JEGERS, K. Cross-media Interaction Design. In HCI and New Media Arts: Methodology and Evaluation. San Jose - CA, 2007. 